\title{
A Platonic Trope Bundle Theory
}

Christopher Buckels

Accepted Author Manuscript (2020) - Ancient Philosophy Today: DIALOGOI 2:2, 91-112.

Abstract: This paper provides a rational reconstruction of a Platonic trope bundle theory that is a live alternative to contemporary bundle theories. According to the theory, Platonic particulars are composed of what Plato calls images of Forms; contemporary metaphysicians call these tropes. Tropes are dependent on Forms and the Receptacle, while trope bundles are structured by natural kinds using the Phaedo's principles of inclusion and exclusion and the Timaeus' geometrized elements, as well as by co-location in the Receptacle. Key elements of discussion include persistence and abundance of Plato's tropes. The resulting theory is compared with contemporary trope bundle theories.

Keywords: Plato, Timaeus, Phaedo, Trope Theory, Bundle Theory, Metaphysics of Particulars

This paper developed out of a dissatisfaction with existing accounts of Platonic particulars, that is, accounts of what things such as Socrates, bees, and stones are on a Platonic analysis. The fundamental requirement for such an account is that particulars participate in Forms in order to have their properties, but this requirement is consistent with many, quite different, accounts of Platonic particulars. Socrates may be what he is 'on his own,' not dependent on any particular Form, only getting his 'accidents' by participating in Forms; that is, he may exist independently of the Forms, and Forms merely explain why he exists the way he does. Alternatively, there may be part of him that exists without any properties itself, a bare particular, that gets all of its properties by participating in Forms. Finally, he may be a mere bundle of those properties provided by the Forms, completely tied to those Forms for his continued existence. This list is by no means exhaustive, and there are subtle variations on each possibility. It seems to me that much of contemporary Platonic scholarship assumes, with or without argument, that Platonic particulars are something like the first and second options mentioned: particulars are what they are independently of the Forms, but they depend on the Forms for many, if not all, of their properties. Of course Plato never lays out his own philosophical positions, since he never appears as a character in his dialogues, so no one can lay unambiguous claim to Plato's own theory. Nonetheless I will defend the final option in the list above as a defensible reading of particulars in Plato's corpus and, in fact, as a superior reading to the first two options. Platonic particulars are bundles of property-instances that depend completely on Forms.

To this end I make two major assumptions, which have been defended elsewhere. First, I assume that the entity introduced as "the Receptacle" in the Timaeus is space rather than any sort 
of substratum. ${ }^{1}$ Second, I assume that the entities Plato variously calls images of Forms, shares of Forms, Forms in us, etc., are tropes, i.e., property-instances. In particular, the entities associated with Becoming, the second of three ontological classes laid out in the Timaeus, are tropes. ${ }^{2}$ On the basis of these assumptions I engage in a project of rational reconstruction, constructing a Platonic trope bundle theory from material in the Phaedo and Timaeus. First, I lay out a Platonic trope theory from the Timaeus and Phaedo, and I discuss the Phaedo's mechanism of inclusion and exclusion of tropes. In this section, I also discuss the persistence, spatial extension, and abundance of tropes, as well their dependence upon Forms - for no truly Platonic theory would endorse trope nominalism. In the second part of the paper, I lay out a Platonic bundle theory, making use of the Phaedo's principles of inclusion and exclusion and the Timaeus' Receptacle and geometrized elements. Here I discuss the structuring of bundles by natural kinds, the relation of bundles and sensible particulars, and the persistence conditions of bundles. The resulting trope bundle theory is thoroughly Platonic in spirit and firmly rooted in Plato's texts, even if one cannot prove that Plato maintained it himself-just as we cannot prove that Plato held any particular philosophical position. I conclude by briefly showing how this Platonic trope bundle theory compares favorably with contemporary trope bundle theories.

\section{A Platonic Trope Theory}

Let us begin with an overview of tropes. A trope is a property-instance. For two objects to be white, for example, is for each of them to have its own instance of whiteness. This white is a trope, and it is distinct from that white. The two instances of white may be the exact same shade of white, qualitatively indistinguishable yet numerically distinct. This one is here, and that one is there. A trope nominalist goes on to say that Whiteness, the universal, is just the sum of all white tropes, but one need not take this next step; Plato certainly does not! Trope theorists debate how tropes are individuated, if they persist or are momentary, and whether they are sparse or abundant; these are all topics we will consider in relation to Plato's trope theory.

As I said, Plato is not a nominalist. His tropes are compatible with, and dependent on, transcendent universals. In contemporary terms, transcendent universals ground Plato's tropes.

\footnotetext{
${ }^{1}$ For defense of the assumption that the Receptacle is space, see Cherniss 1954, Lee 1966 \& 1967, and Buckels 2016b. The latter argues that Plato's descriptions of the Receptacle are incompatible with it serving as substratum (or its parts as substrata) to particulars.

${ }^{2}$ For defense of the assumption that Form images are tropes, see Silverman 2002, p. 313, n. 10, who writes that Form images "are the 'tropes' propounded in the 1920s by Stout, in the 1950s by D. C. Williams and Wilfrid Sellars, and today by various metaphysicians," and Buckels 2018. The latter argues that the entities Plato introduces as $\tau$ à $\tau o 1 \alpha \tilde{v} \tau \alpha$ at Timaeus $49 \mathrm{~d} 5$ are tropes. As many may find this assumption implausible, allow me to mention just two prima facie pieces of evidence for it. First, both the "traditional" and "alternative" translations of 49d5-50a4

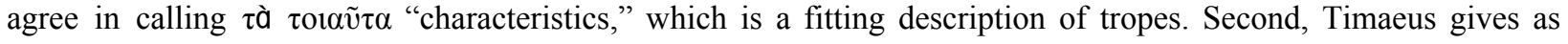
examples of $\tau$ à $\tau o 1 \alpha \tilde{v} \tau \alpha$ "hot," "white," and "everything composed of them" (50a2-4), rather than naming objects. In fact, the very point of the passage, on most translations, is that names refer to characteristics instead of persisting

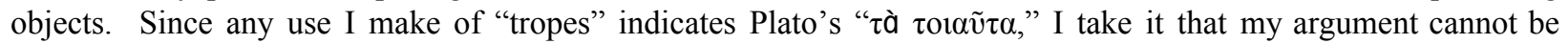
anachronistic. I briefly recount more of the evidence for Platonic tropes in sections I. $i$ and I.iii below; see also note 11.
} 
By calling the Forms transcendent universals, I mean that they lack spatiotemporal locations (Tim. 52a2-3) yet explain the commonality of features located in different spatiotemporal locations (Rep. 596a5-8). ${ }^{3}$ Plato's tropes are dependent upon the Forms: they are images or shares of Forms (e.g., Tim. 48e4-49a1; Phd. 102b1-2). ${ }^{4}$ This white is an image of Whiteness itself. Forms, as eternal, immutable essences, make tropes what they are, so this is fixed and stable. But tropes' existence-that they are-is not fixed and stable. This white will never become not-white, although it may perish, just as it came to be at some time.

Form images are not images in a physical sense, since Forms are not spatio-temporal entities and so have no physical appearance. Form images are temporary spatiotemporal instances of non-spatiotemporal properties; this entails that not all propositions true of a Form will be true of that Form's images. This white is located in a particular time and space and has an appearance. Whiteness itself has no location in time or space and has no appearance, as Plato reveals in the Timaeus: Form images must be in some place (52a6-7), while Forms are in no place at all (52a2-3). Thus Plato's tropes are instances of the property of which they are an image or share, but they are not identical to the property.

\section{i. Tropes in the Phaedo}

As I said above, I assume Plato makes use of tropes, but reviewing the evidence for them in the corpus will help establish the kind of trope theory Plato endorses. So let us first briefly examine Plato's trope theory in the Phaedo. The dialogue unveils a metaphysics in which sensible objects are deficient in comparison to Forms and are continually in danger of breaking up into their constituent properties or parts (78c1-3). Sensation itself, it indicates, is not a reliable guide to truth (65b1-8). The "equals in sensations," for example, are difficult to discern and deficient compared to the Equal itself (75a11-b2). Tropes in the Phaedo are contrasted sharply with Forms: they are associated with plurality, sensation, coming-to-be, and destruction. ${ }^{5}$

We will focus on the discussion following the announcement late in the dialogue that sensibles are named for the Forms of which they have shares (102b1-2). ${ }^{6}$ For example, equal things are named for the equality in them, that is, for their share of equality.

At 102d6-8, Socrates clarifies this announcement by contrasting "the bigness in us" ( $\tau$ ò

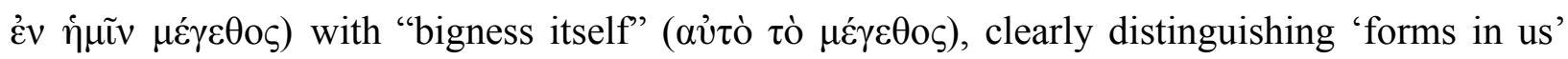
from Forms themselves. The bigness in Simmias, for example, and the smallness in Socrates are

\footnotetext{
${ }^{3}$ All textual references are to the OCT Phaedo of Duke et al., Burnet's OCT Timaeus, or Sling's OCT Republic, and translations are my own, unless otherwise indicated.

${ }^{4}$ In the terms of Schaffer 2009b, Form images are derivative, grounded by Forms, which are fundamental entities. As we will see, Forms images are also grounded by the Receptacle, another fundamental entity.

${ }^{5}$ The Phaedo is concerned primarily with the relation between body and soul. It is a complicated matter, and one I cannot pursue here, whether Plato allows tropes in the soul, especially in the Phaedo, where the soul is associated with simplicity and the unchanging Forms.

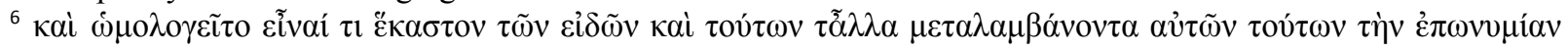

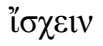


particular instances of the properties being big and being small. These 'forms in us' are properties we possess (103b6), distinct from the Form of Bigness and the Form of Smallness. Since big things and small things are so-named because they have shares of Bigness and Smallness, we should identify those shares of Forms with instances of the properties of being big and being small. In other words, we may use "shares of Forms" interchangeably with "tropes." Having a share of Bigness is to have a bigness trope, just as the "equals in sensations" are equality tropes. This is a clear distinction between sensible tropes and intelligible Forms.

Socrates also reveals that tropes, unlike Forms, perish. When a share of Smallness comes to be in Simmias (because, in the toy example, he is standing next to the taller Phaedo), his share of Bigness (from standing next to the shorter Socrates) must "withdraw or perish" (102d9-e2). In the larger context of the dialogue, the withdraw option paves the way for the soul to withdraw from the body at death rather than perishing (106e4-6). But the soul withdraws to the underworld, while there is nowhere for a share of Bigness to go-it merely perishes. ${ }^{7}$ Thus tropes come to be and perish, unlike the Forms themselves; such a conclusion is not a surprise, since tropes are sensible, and sensible objects are liable to destruction (78c1-3). When an object comes to be $F$, it does so by gaining an $F$ trope, and when it ceases to be $F$, it does so by losing the $F$ trope, which perishes. Depending upon the range of Forms, it may be possible for Socrates to explain all generation and destruction by the generation and destruction of tropes - if a tree is cut into lumber, it would lose the tree trope and gain the lumber trope, and if the tree is somehow completely destroyed, it would lose its tree trope along with all other tropes. We will return to the possibility that Plato endorses such explanations after considering his fully developed trope theory (II. $i$ ).

We have seen that the Phaedo introduces 'forms in us' that are shares of Forms. The possession of these shares explains why a given sensible particular has the properties it does: big things have shares of Bigness, and equal things have shares of Equality. These shares come to be when a sensible particular gains the relevant property and perish when it loses that property. Since the presence or absence of a Form share explains why a particular has or does not have a property, Form shares perform the same function as the tropes of modern metaphysicians, and so may be called tropes without anachronism.

\section{ii. Inclusion and Exclusion in the Phaedo}

\footnotetext{
${ }^{7}$ Cf. Devereux 1994, pp. 67-8; contra Gallop 1975, p. 195, and Fine 1986, pp. 306-8. Silverman 2002 maintains that Form shares do not perish; they "withdraw when necessary and thus continue to be what they are when the particular has perished" (97). Phaedo 106c4-7 makes clear, however, that shares can perish. Socrates establishes that if the uneven were necessarily indestructible, anything uneven would be indestructible as well. He then admits that the uneven is not indestructible (106c4-6). Since "the uneven" must indicate "the odd," i.e., a share of the Form Oddness, Socrates admits that shares of Oddness — and Coldness and the rest (106c6-7) — are destructible.

Even though Form shares may perish, one could still hold that withdrawing does not require them to perish; a share may simply transfer to another object when they withdraw. Such a withdrawal would seem to require "free-floating" tropes that may exist unattached to any object. While some contemporary trope theorists defend such a view, it is not a view Plato seems to consider.
} 
Socrates next describes relations including and excluding Form shares from sensible particulars; these inclusion and exclusion relations are tropes themselves. He has established that shares of opposites such as Bigness and Smallness cannot be in the same object, in the same respect, and at the same time. But there are also other Form shares that cannot be copresent in a particular. Snow, for example, cannot abide heat, even though it is not opposite to heat. Socrates argues that certain Form shares include others in the objects they characterize; Snowiness necessarily includes Coldness and so cannot coexist with the opposite of Coldness, Heat; therefore Heat excludes Coldness (103c13-e1). Not only does the share of Coldness perish from the object upon the advance of a share of Heat, but the share of Snowiness does, too-we are left with a puddle of water where there used to be a hunk of snow. ${ }^{8}$ Socrates explains this so:

So then, Cebes, these are things such that whatever occupies them compels them ${ }^{9}$ not only to have its own form, but also always, in turn, the form of something that is opposite to something (104d1-3). ${ }^{10}$

The "things" under discussion are fire and snow, which are compelled by what occupies them-shares of Fieriness and Snowiness - to have not only these shares but also shares of opposite Forms - shares of Heat and Coldness. In fact, every sensible object has a share of a Form with an opposite, on a fairly uncontroversial definition of "opposite;" for example, every physical object is either warm or cold (i.e., has some temperature).

Even though Plato does not have Socrates explicitly draw this conclusion in the Phaedo, we should note that the inclusion and exclusion relations render substrata unnecessary-there need not be anything that 'has' the tropes, since tropes include and exclude one another. The

\footnotetext{
${ }^{8}$ Nehamas 1973, pp. 467-8, interprets the 'summoners passage' in the Republic (523a10f) as telling against Forms of substances, such as a Form of Human, a Form of Finger, or, here, a Form of Snow. The argument there directly

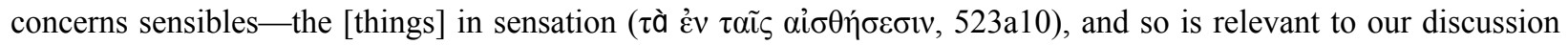
here. The way the argument is set up, the sensibles at issue are hardness, softness, whiteness, blackness, and so on. Among them is also, it seems, 'the finger.' Since the other "things in sensation" appear to be tropes, we must ask whether the passage rules out tropes of Fingerness.

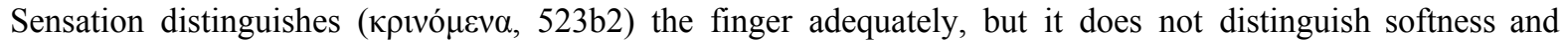
hardness; for these, the intellect must be summoned. In fact, Socrates implies that the intellects of "the few" are summoned in the case of the finger, too, for he notes only that the intellects of "the many" ( $\tau$ à $\pi \mathrm{o} \lambda \lambda \dot{\alpha}, 523 \mathrm{~d} 4)$ are not summoned by the finger. The philosopher will not be satisfied with appearances but will question what a finger really is. The intellect of "the many" is summoned because softness and hardness appear to be in the very same thing, the finger. The intellect, not sensation, determines what softness really is and what hardness really is, just as the intellect of the philosopher may puzzle about what a finger really is, as opposed to what is not a finger. Thus we need not read the argument as forbidding Forms of substances.

There is great similarity between the description of sensibles in the summoners passage and their description in the Phaedo. At Republic 523e3, Socrates refers to the smallness and largeness of the finger, like the largeness and smallness in Simmias. At 523d6, we come across the opposite of finger, which would, in our terms, exclude a share of Finger. At 523e7, touch reveals hardness and softness deficiently, just as the equals we see are deficient compared to the Equals themselves in the Phaedo.

${ }^{9}$ Another reading has: "such that they compel whatever they occupy." See Gallop, pp. 235-6 n. 70, for discussion of the grammatical difficulties in the passage.

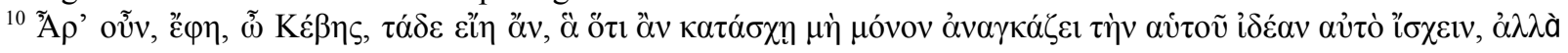

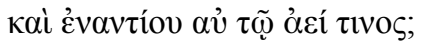


"object" into which shares are included may simply be an aggregate of those Form shares. A share of Wateriness, for example, brings along many other shares - coldness, perhaps, and liquidity, etc. Since the share of Wateriness brings these other shares with it, nothing is needed to unify these disparate tropes; they are already unified by their inclusion with the share of Wateriness. Water, the physical stuff, would be that group of shares that are included with the share of Wateriness. Ordinary, sensible objects in the Phaedo may, then, be composed wholly of tropes, without any substrata. This possibility is exploited later in the Timaeus, where objects will explicitly be said to be composed of "this suches."

\section{iii. Tropes in the Timaeus}

Let us turn to developments in Plato's trope theory in the Timaeus, where Plato's description of the natural world is much more detailed. We begin with a distinction between Being and Becoming (27d5). The members of the class of Being are Forms; the class of Becoming, in turn, is identified with the class of Form images or "copies" ( $\mu$ í $\mu \eta \mu \alpha, 48 \mathrm{e} 4-49 \mathrm{a} 1)$, so that each thing in the class of Becoming is an image of a Form. As I said above, one of the two major assumptions of this paper is that Form images are tropes, or spatiotemporally located particular instances of non-spatiotemporal universals. Thus ordinary particulars are not themselves Form images, but rather they are composed of Form images. For this reason I take Form images in the Timaeus to be identical to Form shares in the Phaedo, although the language of tropes as images plays a significant role in Plato's treatment of particulars in the Timaeus and is a significant change of terminology. Henceforth I use "Form image" and "Form share" interchangeably.

The main support for taking Plato to have a trope theory in the Timaeus comes from 49b1-50a4. Due to considerations of space and to avoid repeating well-trodden arguments, here I will simply lay out an interpretation of this "much misread passage" in summary form and without argument.

First Timaeus focuses on the four traditional elements, saying that we cannot point to any one and call it one stable thing, for each appears to turn into the others. E.g., air apparently condenses into water, which nurtures and becomes part of a tree (earth), which burns (fire) and turns into smoke (air). Instead of calling some apparent object, e.g., a stone, by the name of an element, e.g., "earth," Timaeus instructs us to call "what is this-such on each occasion," e.g, what is always fiery, by the name "fire" (49d4-7). In general, our common names for things should refer to 'this-suches' rather than to things or stuff. He makes this generalization clear: anything that we point to and call "this" or "that" is actually not a stable thing; any predicate assigned to it could fail to apply to it at some point, and it is even possible for a contradictory

\footnotetext{
${ }^{11}$ The interpretation here follows Buckels 2018, which is inspired by Cherniss 1954. See the former for a defense of the claims in this section, as well as for treatment of some of the extensive scholarship on the passage; addressing the secondary literature here would derail my project of laying out a Platonic trope bundle theory. For the so-called "traditional" interpretation of the passage, see Zeyl 2000.
} 
predicate to be assigned to the same stuff (49d7-e4). He gives hot and white (50a2-3) as further examples: we should not call any thing hot, since it could also become cold, nor should we call any thing white, since it could become a different color. But we may call an instance of heat hot, since an instance of heat can never be anything else, and we may call an instance of whiteness white, since that whiteness could never be a different color than it is.

When Timaeus specifies property instances as the proper bearers of names, we should be reminded of the Phaedo. There, sensibles got their names because they possessed shares of the Forms that properly bore those names. Here we receive a correction: strictly speaking, the sensible particular shouldn't be called by that name, but only the property instance it has. An important point remains, however: just as the properties of sensibles in the Phaedo are Form shares, sensibles properties in the Timaeus are this-suches.

Timaeus includes as 'this-suches' not only heat and whiteness and other properties with opposites, but also "everything composed of these" (50a2-4). Since every sensible particular has some temperature and some color, he now includes all sensible particulars in the category of "this-suches." Earlier, he claimed that all sensible things come to be (28b7-c2), and all things that come to be are images of Forms (48e4-49a1). Thus, all this-suches, including all sensible things, are images of Forms. Since "this-suches" and Form images are shown to be coextensive, they are all tropes; this passage indicates that all apparent objects are, in fact, composed of tropes.

\section{iv. Receptacle and Structure}

In the same passage wherein Timaeus tells us not to call apparent objects "this" or "that," we learn that there is something that we may call "this" in a stable way. The Receptacle is not essentially characterized by any $F$, i.e., it has no properties, or at least no properties that correspond to Forms or Form images. Timaeus calls it space ( $\chi \omega ́ \rho \alpha, 52 \mathrm{a} 8$ ), place ( seat ( $ع \delta \rho \alpha, 52 b 1)$ for Form images, and that 'in which' Form images come to be and from which they perish. He says we see the need for the Receptacle when we think about the material world and conclude that everything that comes to be must be in some place (52b3-5). The Receptacle appears to change as Form images come to be and perish from it, but it remains immutable and eternal throughout.

Thus the Receptacle provides a place for tropes to come to be (50c4-5). That is, it functions as another ground for Form images. They depend on Forms for their content and the Receptacle for their spatiotemporal location. It is only by being grounded in both Forms and Receptacle that Form images can have the properties Timaeus describes, such as being sensible, able to come to be and perish, and spatiotemporally located. Yet one may ask, as Aristotle does (De Generatione et Corruptione 335b9-24), how immutable, eternal grounds may produce

\footnotetext{
${ }^{12}$ Tropes have been called "this-suches" in contemporary theories, e.g., Schaffer 2001, p. 247, although Schaffer argues that tropes are better described as "here-suches." I take his point, and Plato's tropes could arguably be called "here-suches" instead, but I will use "this-such" since it is more representative of contemporary trope theories.
} 
something that can come to be and perish. Timaeus answers this question with a scientific account of how Form images in the Receptacle interact with one another based on principles of geometrical structure.

Timaeus explains that the four traditional elements out of which all other bodies are constructed are not really elemental, that is, they are not fundamental. They are themselves built out of more fundamental particles. Timaeus identifies each element with a geometrical structure - one of the Platonic solids - and explains how each structure is constructed from triangles. He does not claim that these triangles are the most basic elements of bodies, but they are, at least, the most basic elements he considers. Thus all bodies are ultimately constructed from elemental triangles, which should be understood to be Plato's fundamental physical particles. The triangles should also be understood to be composed of tropes - each is composed of an image (or instance) of Triangularity and the tropes it includes, such as angle tropes, side tropes, etc. ${ }^{13}$ This view is akin to taking contemporary fundamental particles to be composed of properties such as mass, charge, and spin. When discussing the most fundamental level of the sensible world, then, we should discuss Platonic solids, elemental triangles, and the tropes out of which these are composed, rather than speaking of macroscopic bodies and their tropes. We will return to these structures in part II to see how they enable an account of the formation of bundles of tropes.

\section{v. Persistence of Tropes}

Let us examine two theoretical possibilities for Plato's tropes, first, the issue of their persistence through time and, second, their abundance and scarcity. There are two options vis-à-vis persistence of tropes: either they persist through time or are momentary, non-recurrent particulars. We should examine both options to see which best fits our Platonic trope theory. In the first case, a trope persists at least as long as a given object has a certain property for a certain reason, so that this white exists at least as long as the paper remains white, although another white trope would replace the first if someone splashed white paint on the white paper.

In the second case, where tropes are momentary, non-recurrent particulars, each trope is replaced at each moment by a numerically distinct, qualitatively identical trope. This white lasts only an instant, even though the color of the paper remains unchanged, since this white is replaced instantly by another white trope. Such a picture of the world as composed of instantaneous entities is sometimes called "immaculate replacement;" each entity is replaced anew each moment with no causal connection between the entities. ${ }^{14}$

Indeed, such a picture of the world may be tempting for Plato, who is deemed by some to be sympathetic to a Heraclitean flux doctrine in the Phaedo. There Socrates says, for example,

\footnotetext{
${ }^{13}$ Buckels 2018, 14-19, defends at length the view that triangles are composed of tropes. Briefly, evidence for this view includes Timaeus' identification of a triangle as a 'this-such' at 50a5-d5 and his use of triangles' properties in his scientific explanations, e.g., that the acuteness of angles explains the burning of heat (61d5-62a5).

${ }^{14}$ Cf. Ehring 2001, p. 164-5.
} 
that sensible things are "never the same in any way" (78e3-4). We might think, given Timaeus' treatment of fire and the elements, that the Timaeus gives us the same radical picture of sensible reality, such that it is always changing. One might even think that the elemental triangles that compose all other bodily things constantly undergo immaculate replacement.

There are good reasons to doubt that Plato endorses immaculate replacement. ${ }^{15}$ Elemental triangles must persist long enough to enable a bit of fire to transform into a bit of air - the same triangle that once partially constituted fire now partially constitutes air, and so it seems that the tropes that compose those triangles also persist (Tim. 57b3). I say that it "seems" so, not that it must be so, because one may posit that the tropes are immaculately replaced while the triangles themselves remain the same. But this position is unmotivated by the text (and perhaps philosophically unmotivated) once one has admitted that the triangles so composed persist from one moment to the next. We do not have a reality of radical flux in the Timaeus. It need only be the case that the triangles - and their constituent tropes - could perish at any moment, not that they do, in fact, perish after a single instant.

\section{vi. Abundance of Tropes}

There is another decision confronting us in attributing a trope theory to Plato: does he endorse a sparse or an abundant trope theory? The latter gives us a trope, or a class of tropes, for each and every property, no matter if that property is ever instantiated or even, according to some trope theorists, if the property cannot ever be instantiated. The former theory limits the kinds of tropes in its ontology, generally to several basic tropes out of which all other properties may be constructed.

In the Timaeus Plato takes steps toward a sparse trope theory, which is surprising, since he is often held to countenance a wide range of Forms. A complete scientific account of the physical world would likely indicate, Plato seems to think, that some predicates need not have corresponding Form images. Timaeus' scientific "likely story" postulates elemental triangles as fundamental particles of the physical world. The predicates of these particles have corresponding Form images, but other predicates may be reducible to the Form images that compose fundamental particles. For example, heat is said to be a consequence of the shape of elemental triangles (61d5-62a5), so there need not be a distinct Form image of heat.

The size of ordinary objects may also be reduced, in this case to the size, number, and arrangement of elemental triangles. If there is a Form image of Size, it need only apply to these fundamental particles, not to ordinary material objects. In fact, size also seems reducible; the absolute nature of the Receptacle allows us to be reductionists about properties such as distance and size. Distance may be a relation between regions of space (Receptacle), measured using the sides of fundamental triangles as units, similar to using Planck length as a fundamental natural unit. Size may be the amount of space occupied in the Receptacle, again measured by the sides

\footnotetext{
${ }^{15}$ See Buckels 2018, 17-18, for further reasons and discussion.
} 
of fundamental triangles. Accordingly, there seems to be no need of Forms of Distance and Size, just as there is no need for a Form of Heat. While Plato may not have subscribed to a sparse theory of Forms, he certainly has the theoretical equipment to construct one, and such a sparse trope theory seems remarkably similar to contemporary trope theories.

The trope theory of the Timaeus does, however, differ in a significant respect from contemporary sparse trope theories, namely, in including tropes of natural kinds such as species and elements. There is explicit mention of a Form of Fire (Tim. 51b8), just as Fire was mentioned in the Phaedo alongside Snow (Phd. 103c10-e5). We also find Man and Ox in the Philebus (15a1-7). Parmenides finds Socrates unsure about Forms of Man, Fire, and Water (130c1-4). Timaeus also mentions and makes significant use of the Form of Living Creature, which contains within itself all intelligible living things, i.e., all species Forms, and of which the universe itself, taken as a whole, is an image (29a6-30d1). While Plato does not draw a lot of attention to these natural kind Forms of animals and elements in the Timaeus or Phaedo, we will see that these natural kind Forms and their images play a significant role in a Platonic bundle theory.

Before we turn to this theory, let us review our Platonic trope theory. Tropes, which are variously called Form shares, this-suches, or Form images by Plato, explain the properties of sensible particulars. These tropes come to be and perish, such that their coming to be explains a sensible particular gaining a property and their perishing explains the loss of a property. They could perish at any time, although they may also persist for a length of time. Not only are tropes distinguished from Forms because they come-to-be and perish, but also because many tropes could all be images of one Form, from which they get their name. E.g., the whiteness of a piece of paper is a whiteness trope, a share or image of the Form White, and the possession of this trope earns the paper the name "white." A different piece of paper has a distinct whiteness trope that is an image of the same Form White. In the Timaeus, Plato takes steps toward a scientific theory whereby the presence of a trope (or a certain combination of tropes) may explain several sensible properties. For example, the acuteness of an angle of an elementary triangle may explain the temperature of the object containing that triangle and its tendency to damage human skin by burning. Substituting our modern scientific theory, we might say that the presence of a negative charge (trope) in an atom explains the shock and flash of an electrostatic discharge (sensible phenomena).

\section{A Platonic Bundle Theory}

If a trope theorist claims that a thing has a property when it has a trope of that property, a trope bundle theorist claims that such tropes suffice to explain material objects. Ordinary material objects are bundles of tropes. This bundling is often explained with compresence; compresent tropes are bundled, and material objects are bundles of tropes. For Plato, co-location in the Receptacle plays the role of compresence, such that a bundle is a sum of co-located tropes.

Bundle theories are characterized by their rejection of substrata; nothing need underlie a 
sum of tropes to unify them into one object. A red ball is composed of a redness trope, a sphericality trope, and all the rest of its tropes, not composed of its tropes plus something else that has the tropes. A human being is likewise a bundle of tropes. ${ }^{16}$ Thus the Receptacle's role is to be space, not substratum: tropes are co-located in the Receptacle, but that location is not thereby the substratum or bearer of those tropes. Although this is not uncontroversial, for our purposes I take the Receptacle to be absolute, i.e., non-relative, space rather than substratum. Property-instances are, in a way, 'reflected' in space; they are dependent upon the Receptacle just as reflections are dependent upon a mirror. A mirror does not act as a substratum to the images upon it, for they glide over its surface, bound to no specific part of it. While a substratum moves with its properties, the Receptacle, like a mirror, is unaffected by the images in it. Reflections are also dependent on the object casting the reflection; just so, Form images are dependent upon Forms for the content that is reflected in the Receptacle. ${ }^{17}$ Thus, as we saw above (I.iv), Forms images have two grounds: Forms and the Receptacle.

The basis for a Platonic bundle theory comes from Timaeus himself: anything that we point to and call "this" or "that" is not a stable thing but a this-such (49d7-e4), and anything composed of this-suches is itself a this-such (50a2-4). In other words, there are no 'things with properties' or 'substrata with properties;' there are only properties and composites of properties. Claiming that an apparent object is a bundle of tropes amounts to no more than this, namely, calling a sensible particular a composite of this-suches.

\section{i. Structuring Bundles}

Let us first examine some of the technical details of bundling tropes. Plato's bundles are individuated at a time by co-location; a bundle is a maximal collection of co-located tropes. ${ }^{18}$ The Receptacle may be divided into regions; at the lowest level Plato explicitly considers, images of Triangularity carve the Receptacle into triangular regions. Any given image of Triangularity is co-located with images of Angularity, Laterality, and whatever other properties we may attribute to triangles (cf. Tim. 54a1-7), forming a bundle at that region of the Receptacle. This bundle may be part of a larger bundle, in which case the location of the larger bundle overlaps the location of the smaller one. Form images (tropes) may thus be spatially extended, since the image of Triangularity is extended across an entire triangular region, just as an image of Humanity extends across an entire human-shaped region (cf. 36d8-e4).

\footnotetext{
${ }^{16}$ As I note above (n. 5), I do not here address the problem of Platonic souls, which is complicated enough to merit separate treatment. Given that souls in the Timaeus seem to be spatially extended and made of more basic components, there may be cause to take souls to be bundles, just as human beings are. Alternatively, they may be entities somehow between the Forms and Form images that play a mediating role.

${ }^{17}$ Cf. Lee 1966 \& 1967 and Mohr 2005, 90-99. See Buckels 2016b for more extensive treatment of the claim that the Receptacle is space rather than substratum.

${ }^{18} x$ is a bundle $=_{\mathrm{df}}$ there is a location $L$, a time $t$, and a non-empty set $S$ of tropes such that: (i) $x$ is located at $L$ at $t$, (ii) each member of $S$ is located at $L$ at $t$, (iii) each trope that is located at $L$ at $t$ is a member of $S$, (iv) each member of $S$ is a constituent of $x$ at $t$, and (v) each constituent of $x$ at $t$ shares-at- $t$ some constituent with some member of $S$.
} 
Given that bundles are collections of co-located tropes, we may ask whether bundles are tied to one location or persist through movement and time. Prima facie, it seems that there would be a new bundle as soon as some tropes move to another location, because those tropes are located in a different region of the Receptacle than they were previously. In fact, it seems there must be a new bundle if even one trope moves to another location or perishes, for there would be a different collection of tropes at the original location: the original collection minus one. This would make Plato a mereological essentialist, endorsing the thesis that a thing has all its parts essentially, i.e., that it becomes a distinct thing if it loses even one part. When I have a haircut, according to a mereological essentialist, I become a new entity. Just so, losing a trope would cause one bundle to perish and another to come into being.

Nothing in the dialogues suggests, however, that Plato endorses such a view of bundles. ${ }^{19}$ Bundles are not tied to locations, nor do they perish when they lose a member trope. While a bundle is individuated at a time by co-location in the Receptacle, the bundle persists as long as it has as a constituent an image of a single natural kind Form.

As we saw above (I.vi), Plato mentions natural kind Forms in the Timaeus and elsewhere e.g., animal and element Forms. Natural kind properties structure bundles by the inclusion and exclusion relations (see I.ii). E.g., if an image of Fire is a constituent of $x$, then an image of Heat is also a constituent of $x$ (cf. Tim. 61d5-62a5) and the two images are co-located in the same region of the Receptacle (cf. Tim. 52d4-e1, Phd. 105b8-c2). ${ }^{20}$ Conversely, an image of Cold cannot be a constituent of $x$ if an image of Fire is a constituent of $x$ (cf. Phd. 103d10-12). ${ }^{21}$

As long as a bundle retains an image of one natural kind Form, then it also retains all the Form images included with that natural kind Form image, or, at least, it always has an appropriate replacement for any trope that perishes (cf. Phd. 102e3-5). When Socrates stands in the sun too long, for example, he might lose his image of Paleness, but his image of Humanity ensures that he always has some skin color. In this way, the same bundle may persist through time even through the loss of tropes and change of location. ${ }^{22}$ Since a given bundle may have several natural kind Form images, it persists until it loses the final one. For example, when a clay statue is flattened, it loses the statue natural kind, if there is such a kind, but retains the clay natural kind, so the object can be said to persist even though we would no longer call it a statue. For an object to perish entirely would be for it to lose all natural kind tropes.

\footnotetext{
${ }^{19}$ For detailed examination of Plato's mereological commitments, see Harte 2002.

${ }^{20}$ Whenever an image of $\mathrm{F}$ " includes" an image of G:

$\forall \mathrm{x}(\exists \mathrm{y}($ Constituent $(\mathrm{y}, \mathrm{x}) \& \operatorname{ImageOf}(\mathrm{y}, \mathrm{F})) \rightarrow \exists \mathrm{z}(\operatorname{ImageOf}(\mathrm{z}, \mathrm{G}) \& \operatorname{Constituent}(\mathrm{z}, \mathrm{x})))$, where Constituent(y, $\mathrm{x})$ means that $y$ is a constituent of $x$ and $\operatorname{ImageOf}(y, F)$ means that $y$ is an image of $F$.

${ }^{21}$ In turn: $\forall \mathrm{x}(\exists \mathrm{y}$ (Constituent(y, x) \& ImageOf(y, F)) $\rightarrow \neg \exists \mathrm{z}(\operatorname{ImageOf}(\mathrm{z}, \mathrm{G}) \&$ Constituent( $(\mathrm{z}, \mathrm{x})))$.

${ }^{22}$ For any bundles $b_{1}$ and $b_{2}$, locations $L_{1}$ and $L_{2}$, and instants $t_{1}$ and $t_{2}$, if $b_{1}$ is located at $L_{1}$ at instant $t_{1}$ and $b_{2}$ is located at $L_{2}$ at instant $t_{2}$, then $b_{1}=b_{2}$ if and only if: there is a spatiotemporally continuous series $P$ of $<$ location, instant> pairs whose first member is $\left\langle L_{1}, t_{1}\right\rangle$ and whose last member is $\left\langle L_{2}, t_{2}\right\rangle$, and there is a natural kind Form $K$ such that: for each member $\langle L, t>$ of $P$, there is a bundle $b$ of Form images that is located at $L$ at $t$ and that has an image of $K$ as a constituent.
} 
The story becomes more sophisticated when we acknowledge the sparseness of Plato's trope theory. Elements are structured bundles; an image of Fire is a structure that is 'filled in' with triangles. In fact, an image of Fire comes into being when triangles are configured in a certain way (Tim. 54d5-55a4). ${ }^{23}$ An image of Triangularity also includes certain Form images, such as being right-angled, trilateral, shaped, and so on. In other words, a fire trope comes to be in a region if and only if a certain configuration of triangle tropes come to be in that region, and the triangle tropes come to be in the region just in case certain other tropes, such as angle tropes, shape tropes, etc., come to be in that region. Since the elemental triangles are themselves bundles, there are structured bundles even at the elemental level.

\section{ii. Bundles and Particulars}

Given that bundles persist through time as maximal, structured collections of tropes, we may ask: do particulars also exist? It is possible to dispense with particulars in our ontology all together, as an eliminativist does, since bundles appear to do the job of particulars. We might even want to be eliminativists about bundles and merely speak of tropes. Given that Plato seems to want to reduce particulars to tropes, this is an attractive option. Alternatively, he may endorse a milder form of reductionism, holding that all particulars are bundles, and all bundles are collections of tropes, but particulars and bundles really do exist.

To determine where Plato falls on this question, recall that Timaeus has told us not to call anything to which we can point - any particular or stuff - by any name. The particular does not have its properties permanently, and so we should not say that $i$ s. When Timaeus says not to give a particular any name, it seems to indicate that particulars do not exist. We should only name the 'this-suches', the tropes, that compose it.

But there are several reasons to think Plato retains particulars in his ontology. First, the Timaeus, taken as a whole, is an account of the generation of the universe, which is an ensouled body - a particular (34b3-4). Additionally, much of the Timaeus is about particulars, not about the tropes that compose particulars, so we should require clear evidence that Plato is an eliminativist before doing away with particulars. Even though there is a reasonable excuse for Timaeus to drop the metaphysically perspicuous way of speaking he employs in the 'much misread passage,' since it would be difficult to keep it up for the entire dialogue, it is doubtful that Plato wants to exclude particulars from his ontology completely. Instead, we should recognize the difference between his fundamental ontology and his expanded ontology. ${ }^{24}$ While tropes are fundamental, particulars and bundles are derived entities. Thus tropes are the grounds for particulars and bundles, which are fully dependent upon their constituent tropes and have no

\footnotetext{
${ }^{23}$ This is the case, at least, if our sparse trope theory contains a Form of Fire rather than a certain combination of triangle tropes that makes it true that a given thing is fiery. Cf. Harte 2002, p. 262 and n. 189.

${ }^{24}$ Plato makes a similar move in the "Secret Doctrine" passage of the Theaetetus. See Buckels 2016a. See also Schaffer 2009b, 373-4, for contemporary exploration of fundamental and derived entities and grounding.
} 
other constituents besides 1) tropes or 2) parts that are composed of tropes. ${ }^{25}$ Our basic ontology includes only Forms, Form images, and the Receptacle (Tim. 52d2-4), where Form images are understood to be tropes, not bodies. Even tropes are not entirely fundamental, since they are grounded in Forms and the Receptacle. When we consider our expanded ontology, we include bundles and particulars; these are derived from and grounded by ontologically more basic constituents, Form images.

So what is the difference, if any, between bundles and particulars? There are two main options. On the one hand, bundles and particulars may be identical; on the other, the two may be distinguished, perhaps by their persistence conditions. Above we said that a bundle persists through time as long as it contains an image of a single natural kind Form, even though a bundle is unified at a time by co-location in a region of the Receptacle. We could modify this picture so that a bundle is a sum of tropes at a location at a time whereas a particular is a sum across time of bundles that 1) have as a constituent an image of a given natural kind Form and 2) are parts of a spatiotemporally continuous series. In other words, the identity conditions of a bundle at a time could be separate from the identity conditions of a bundle over time, marking the first as a bundle and the second as a particular. ${ }^{26}$ Thus Plato would be a mereological essentialist about bundles, since a bundle would cease to exist when at least one of its constituent tropes changed location or ceased to exist, but he would not be a mereological essentialist about particulars, since particulars could gain or lose tropes and could change location freely, as long as they did not lose their natural kind trope.

While this is an appealing picture, and it would allow us to easily distinguish bundles and particulars, Plato nowhere distinguishes the two. Thus we should identify particulars with bundles, rather than distinguishing the two, at least if we want to follow Plato. In addition, there does not seem any great benefit in distinguishing two kinds of derivative entities instead of one kind, so we do not lose any explanatory power in our theory by identifying particulars and bundles.

\section{iii. Persistence Conditions of Bundles}

While bundles persist through time by having the same natural kind Form images, it is not thereby necessary for Form images themselves to persist through time. In other words, specifying the persistence conditions for bundles does not lock us into an account of the persistence of tropes, although we dealt with this latter issue above (I.v). Bundles persist by having as a constituent an image of the same natural kind Form at every instant of their existence, which is compatible with an exactly similar natural kind trope existing at every instant of the bundle's existence. Thus, our bundle theory is compatible with an immaculate replacement account of tropes, that is, an account whereby 1) tropes are momentary, nonrecurrent particulars and 2) a property counts as the same property over time if there is a spatially and temporally

\footnotetext{
${ }^{25}$ See McPherran 1988 and White 1981 for arguments that Plato's particulars also have substrata.

${ }^{26}$ Cf. Casullo 1988 \& Simons 1994.
} 
continuous path linking exactly similar tropes. While this sort of explanation of property persistence is open to Plato, there is good evidence that he rejects such a view in favor of Form shares that can persist through time, as we saw above. In the end, Plato does not seem to think that sensible particulars are changing in all ways at all times, only that they may change in every way at any time.

To summarize, particulars are derived entities in the ontology of our Platonic trope bundle theory and are identical to bundles of tropes. Particulars are derived entities because they are entirely dependent on their grounds: their constituents, i.e., tropes, and the space they occupy, i.e., a region of the Receptacle. A bundle is a maximal, structured collection of tropes, where all of its constituent Form images are co-located at a time in a region of the Receptacle. A bundle persists through time as long as it contains an image of a given natural kind Form, which includes and excludes other Form images.

\section{Conclusion}

Let us briefly compare our Platonic Trope Bundle Theory with contemporary theories. Plato takes steps toward a sparse trope theory, which is popular among contemporary trope theorists for its ontological parsimony. ${ }^{27}$ Such a theory is conducive to explaining modern quantum physics, which tends to reduce particles to their properties. Of course, contemporary trope theorists are likely to point to one aspect of Plato's theory that is not parsimonious: the fact that tropes exist alongside transcendent universals. This seems unnecessary, since tropes can do everything universals can do: the universal Redness just is the set of all red tropes, Trope Nominalists hold. With one fell swoop we could make Plato's tripartite ontology into a dualism. Some would go a step farther and discard the Receptacle, too, in favor of relative space; this leaves a one category ontology.

There are several reasons why Plato would not endorse these changes. First, discarding the Receptacle would leave no account of co-location, which would have to be replaced with a compresence relation. But this might not be too damaging, since inclusion and exclusion relations can be the 'ontological glue' that binds bundles. From Plato's point of view, the bigger problem would be to leave particulars as fundamental entities; they would no longer have a 'cosmic mirror' in which they are reflected but would stand on their own. They would be substances, whereas the status of substance should, leaving Forms aside, apply only to the Receptacle, making Plato a supersubstantivalist about space. ${ }^{28}$

Abandoning the Theory of Forms would also leave sensible particulars as fundamental entities. Plato's primary objection to this move would likely be epistemological (Tim. 51d3-7). Without Forms, human intellects have no objects to know. We cannot, he argues, know sensible

\footnotetext{
${ }^{27}$ E.g., McDaniel 2001, pp. 271-2. Cf. Ehring 2011.

${ }^{28}$ Cf. Schaffer 2009a. The Receptacle is space, but not time, so Plato's supersubstantivalism would differ from contemporary supersubstantivalism about spacetime. See Buckels $2016 \mathrm{~b}$ for further discussion of the differences between the Receptacle as absolute space and contemporary supersubstantivalism.
} 
particulars, for they change; they are not what they are in a stable way. Knowledge, for Plato, requires a stable object, and Form shares cannot fulfill this role, since they pass in and out of existence. $^{29}$ There must be eternal, immutable Forms that stand as objects of knowledge, since particular instances of properties are not stable enough for us to grasp with the firmness required for true understanding.

Platonic Forms bring one other advantage when paired with a trope theory. Unlike most contemporary theories, Plato has an easy way to explain resemblance among tropes: two tropes are exactly similar if and only if they are images of the same Form. Lesser degrees of resemblance are also explained by appeal to Forms, specifically, by appeal to relations among Forms. Plato may be pursuing precisely this, i.e., the project of mapping relations among Forms, in his method of Collection and Division, which defines a term (or Form) in terms of its place in a taxonomy of terms (or Forms). Lower Forms in the taxonomical ladder are related to higher Forms as parts. If there is a Form of Human Being, for example, then it is related, as species to genus, or part to whole, to the Form of Animal, just as is the Form of Dog. By virtue of these facts, a human being (an image of Human Being) is similar to a dog (an image of Dog), in that they are both animals (Human Being and Dog are parts of Animal). This part-whole relationship between lower and higher Forms is confirmed in the Timaeus, where intelligible living things - Forms of animals — are parts of the Form of Animal (30c2-d1).

Thus Plato's combination of tropes with Forms gives him an advantage in ideology, even though it is accompanied by an expanded ontology, in relation to contemporary trope theorists. I doubt many trope theorists will think that this trade-off is worth the cost, but perhaps transcendent realists would be more likely, on these grounds, to endorse a trope bundle theory over a substratum theory where bare particulars instantiate transcendent universals. ${ }^{30}$

\section{Works Cited}

Buckels, Christopher. 2018. "Triangles, Tropes, and $\tau$ à $\tau o ı \alpha \tilde{u} \tau \alpha:$ A Platonic Trope Theory. Plato Journal 18, 9-24.

... 2016a. “The Ontology of the Secret Doctrine in Plato's Theaetetus," Phronesis 61:3, 243 259.

... 2016b. "Making Room for Particulars: Plato's Receptacle as Space not Substratum," Apeiron 49:3. $303-328$.

\footnotetext{
${ }^{29} \mathrm{Cf}$. Silverman 2002, who seems to allow knowledge of form-copies, since they possess essences and knowledge is of essence; see, e.g., p. 86. Silverman's form-copies are, however, better candidates for objects of knowledge than my Form shares, since his form-copies cannot be generated or destroyed.

${ }^{30}$ I would like to thank Cody Gilmore, Christopher Healow, and an anonymous referee for Ancient Philosophy Today: Dialogoi for valuable comments on this paper, as well as audiences at the New England Consortium for Ancient Philosophy, the Central Division meeting of the American Philosophical Association, the London Ancient Science Conference, and the Trinity College Dublin Philosophy Colloquium for discussion of some of the parts of this paper. I thank Peter Larsen, Vasilis Politis, and Jan Szaif for discussion of previous versions.
} 
Casullo, Albert. 1988. “A Fourth Version of the Bundle Theory.” Philosophical Studies 54: 125 -39 .

Cherniss, Harold. 1954. "A Much Misread Passage of the Timaeus (Timaeus 49C7-50B5)." The American Journal of Philology 75: 2. 113 - 130.

Devereux, Daniel. 1994. "Separation and Immanence in Plato's Theory of Forms." Oxford Studies in Ancient Philosophy 12. 63 - 90.

Ehring, Douglas. 2011. Tropes: Properties, Objects, and Mental Causation. Oxford University Press.

... 2001. "Temporal Parts and Bundle Theory" Philosophical Studies 104: 2. 163 - 168.

Fine, Gail. 1986. "Immanence." Oxford Studies in Ancient Philosophy 4. 71 - 97.

Gallop, David. 1975. Plato: Phaedo. Oxford: Clarendon Press.

Harte, Verity. 2002. Plato on Parts and Wholes: The Metaphysics of Structure. Oxford: Clarendon Press.

Lee, Edward. 1967. “On Plato's Timaeus, 49D4-E7.” The American Journal of Philology 88: 1. 1 $-28$.

... 1966. "On the Metaphysics of the Image in Plato's Timaeus." The Monist 50. 341 - 368.

McDaniel, Kris. 2001. “Tropes and Ordinary Physical Objects.” Philosophical Studies 104. 269 -290 .

McPherran, Marc L. 1988. “Plato's Particulars.” The Southern Journal of Philosophy 26: 4. 527 $-553$.

Mohr, Richard D. 2005. God and Forms in Plato. 2nd edition. Parmenides Publishing.

Mohr, Richard and Barbara Sattler. 2010. One Book, The Whole Universe: Plato's Timaeus Today. Las Vegas: Parmenides Publishing.

Schaffer, Jonathan. 2009a. "Spacetime the One Substance." Philosophical Studies 145: 131 148.

... 2009b. "On What Grounds What." In Metametaphysics: New Essays on the Foundations of Ontology. Oxford: Oxford University Press. 347 - 383.

... 2001. "The Individuation of Tropes." Australasian Journal of Philosophy 79: 2. 247 - 257.

Silverman, Allan. 2002. The Dialectic of Essence. Princeton: Princeton University Press.

Simons, Peter. 1994. "Particulars in Particular Clothing: Three Trope Theories of Substance." Philosophy and Phenomenological Research 54: 3. 553 - 575.

White, F. C. 1981. Plato's Theory of Particulars. New York: Arno Press.

Zeyl, Donald. 2000. Plato: Timaeus. Indianapolis: Hackett. 